\title{
25
}

\section{Validating the Rain-Runoff Kernel Function in RUNOFF against Laboratory Experiment}

including super-critical laminar flows

William James

An attempt is made to validate the central rain-runoff algorithm in SWMM. PCSWMM is used to calibrate the kernel function and generate plots that are compared to the experimental results obtained from a laboratory rig whose impervious pavement had a $0.025 \mathrm{~m} / \mathrm{m}$ slope over an area of $2.11 \mathrm{~m}^{2}$ and was $1.171 \mathrm{~m}$ wide. A small computational time step of $1 \mathrm{~s}$ was used. Results indicate that the RUNOFF algorithm produces reasonable results. It is shown that supercritical laminar flow cases are included in the validation tests.

\subsection{Introduction}

In this chapter the rain-runoff algorithm that forms the kernel function of the RUNOFF module of SWMM is briefly reviewed, and then run against laboratory data obtained by Johanson (James and Johanson, 1999). This was done because the data from the landmark studies by Izzard (1944, 1945; Izzard and Augustine, 1943) were not as readily available. The laboratory rig used is described in an earlier monograph in this series (James et al., 1999). PCSWMM is used to calibrate and generate plots since Runoff by itself does not produce readable output for such small areas. The term kernel function is used to describe the core algorithm in Runoff that transforms a rain hyetograph into an overland flow hydrograph, since the procedure is analogous mathematically to

James, W. 2001. "Validating the Rain-Runoff Kernel Function in RUNOFF against Laboratory Experiment - including super-critical laminar flows." Journal of Water Management Modeling R207-25. doi: 10.14796/JWMM.R207-25.

(C) CHI 2001 www.chijournal.org ISSN: 2292-6062 (Formerly in Models and applications to Urban Water Systems. ISBN: 0-9683681-4-X) 
convolution. The method uses a simple non-linear reservoir algorithm that does not explicitly account for the basic underlying fluid mechanics processes. A manual method of storage routing with time lag (Falk and Niemczynowicz, 1979 ) is then used to generate tables of Froude and Reynold's numbers. Results demonstrate that the validation cases examined include super-critical laminar flow (a condition not reported elsewhere in the literature).

\subsubsection{Overland Flow Routing in SWMM}

This part is abstracted from the SWMM-RUNOFF documentation (Huber et al., 1988). Only the mathematics of overland flow routing is reviewed - snowmelt, evaporation, infiltration, and groundwater are not discussed in this chapter.

In SWMM-RUNOFF all subcatchments are assumed to be rectangular and each subcatchment is schematized so that three subareas (four if snowmelt is simulated) are used to represent different surface properties. The slope of the idealized subcatchment is in the direction perpendicular to the width. Flow from each subarea moves directly to an outlet and does not pass over any other subarea. (Thus, it is not possible to route runoff from roofs over lawn surfaces, for instance). Subcatchments are subdivided into three subareas that simulate impervious areas with and without depression storage, and pervious area (with depression storage and infiltration). These are areas $A 1, A 3$, and $A 2$ respectively in Figure 25.1. Of course, real subcatchments seldom exhibit the uniform rectangular geometries shown in Figure 25.1. In our case, however the laboratory pavement met these conditions, and corresponded to subarea $A 3$, the subarea without depression storage.

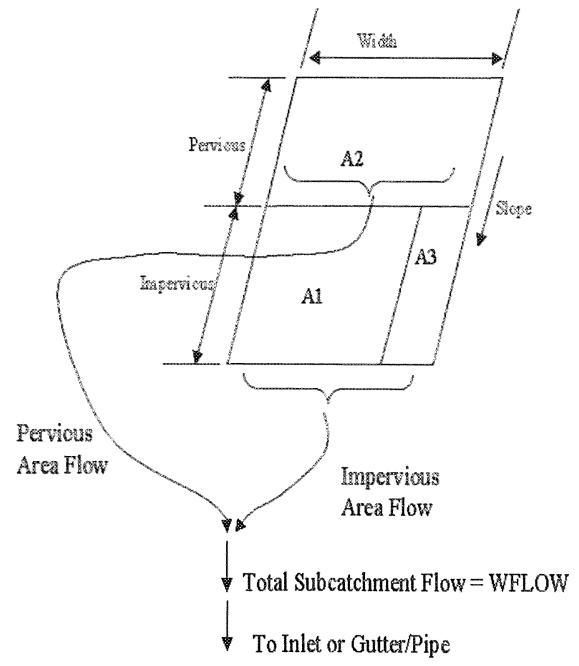

Figure 25.1 Subcatchment schematization. 


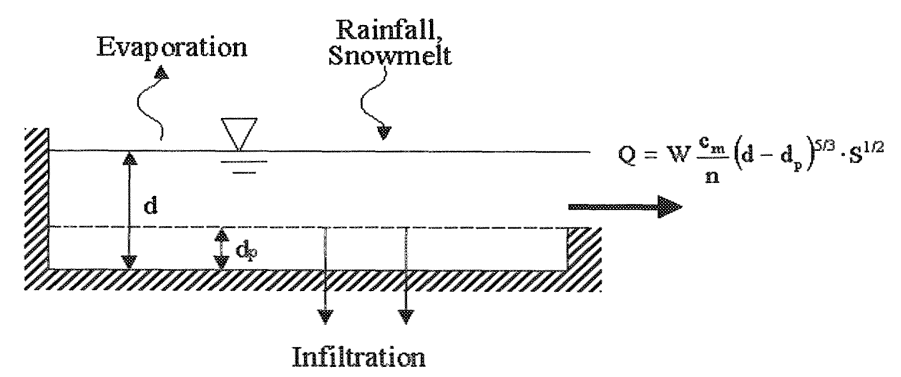

Figure 25.2 Overland flow concept - depression storage is averaged over the area. (Adapted from Huber et al., 1988).

Each subarea flows instantaneously to an outlet node. Flow from one subarea is not routed over another. (Adapted from Huber et al., 1988).

Overland flow is generated from each of the three subareas by approximating them as non-linear reservoirs, as sketched in Figure 25.2. The width (and the slope and roughness) may generally be considered calibration parameters, but this approach was not adopted in this study. Instead the depression storage (which includes initial surface wetting) and Manning's n were used.

The non-linear reservoir concept used in the Runoff kernel function is established by coupling the continuity equation with Manning's equation (Huber et al., 1988). An equation for $d d / d t$ is solved at each time step by using Richardson's extrapolation to the limit. For this purpose, the net inflow and outflow on the right hand side of the equation must be averaged over the time step. The rainfall excess $i *$ is given in the program as the time step average. The average outflow is approximated by using the average between the old and new depths.

If subscripts 1 and 2 denote the beginning and the end of a time step, respectively, the equation is:

$$
\frac{d_{2}-d_{1}}{\Delta t}=i^{*}+W C O N \cdot\left[d_{1}+\frac{1}{2}\left(d_{2}-d_{1}\right)-d_{p}\right]^{\frac{5}{3}}
$$

where:

$$
\begin{aligned}
d= & \text { water depth, } \mathrm{m}, \\
t= & \text { time step, } s . \\
i^{*}= & \text { rainfall excess, } \\
= & \text { rainfall or snowmelt intensity }- \\
& \text { evaporation/infiltration rate, } \mathrm{m} / \mathrm{s} \\
d_{p}= & \text { depth of depression storage, } \mathrm{m}
\end{aligned}
$$




$$
W C O N=\frac{c_{m} \cdot W \cdot S^{1 / 2}}{A \cdot n}
$$

$$
\begin{aligned}
A & =\text { surface area of subcatchment, } \mathrm{m}^{2}, \\
W & =\text { subcatchment width, } \mathrm{m}, \\
c_{m} & =\text { unit conversion constant } \\
& =1 \text { for } \mathrm{SI}(\mathrm{m}-\mathrm{s}) \text { units } \\
& =1.49 \text { for U.S. Customary (ft-s) units } \\
n & =\text { Manning's roughness coefficient, } \\
S & =\text { subcatchment slope, } \mathrm{m} / \mathrm{m} .
\end{aligned}
$$

The subcatchment outflow rate $\mathrm{Q}\left(\mathrm{m}^{3} / \mathrm{s}\right)$ is generated using Manning's equation:

$$
Q=W \cdot \frac{c_{m}}{n}\left(d-d_{p}\right)^{5 / 3} S^{1 / 2}
$$

\subsection{Validation Tests of SWMM-Runoff}

An attempt was made to validate the Runoff kernel against the findings of the previous sections. Four tests were run and plots were generated, calibrated, and compared to the experimental results using a laboratory rig described earlier (James and Johanson, 1999; James and Wylie, 1999; James et al., 1999).

\subsubsection{Input Data Files}

The input files were constructed based on the conditions applicable to overland flow in the laboratory rig. The pavement was $100 \%$ impervious, with a 0.025 $\mathrm{m} / \mathrm{m}$ slope over an area of $0.000211 \mathrm{ha}$. The width was $1.171 \mathrm{~m}$. A small computational time step of $1 \mathrm{~s}$ was used since the flow rates were expected to be small. Table 25.1 outlines the rainfall parameters used in the simulation.

Each test was run in PCSWMM98, then overlaid upon the observed hydrograph points of Johanson (1967). Tests 1 and 2 required calibration to better fit the data. The difference between the observed and the calculated flow rate was then applied to the rainfall intensity input in RUNOFF. SWMMRUNOFF was re-run and results compared again. The resulting peak flow rates differed by less than $1 \%$ in each run. 
Table 25.1 Summary of SWMM-RUNOFF rainfall parameters.

\begin{tabular}{ccccc}
\hline Parameter & $\begin{array}{c}\text { Test \#1 } \\
\text { (Fig.25. 3) }\end{array}$ & $\begin{array}{c}\text { Test \#2 } \\
\text { (Fig. 25.4) }\end{array}$ & $\begin{array}{c}\text { Test \#3 } \\
\text { (Fig. 25.5) }\end{array}$ & $\begin{array}{c}\text { Test \#4 } \\
\text { (Fig. 25.6) }\end{array}$ \\
\hline $\begin{array}{c}\text { Intensity } \\
(\mathrm{mm} / \mathrm{h})\end{array}$ & 117.5 & 120.3 & a) 82.5 & a) 122.1 \\
$\begin{array}{c}\text { Duration } \\
(\mathrm{s})\end{array}$ & 120 & 60 & b) 121.2 & b) 83.1 \\
& & a) 60 & a) 60 \\
\hline
\end{tabular}

Initial rainfall, $a$, is followed by $b$, at given intensity and duration.

\subsubsection{Results}

Figures 25.3 to 25.6 represent the results of the SWMM-RUNOFF runs for each test. Each figure represents the generated SWMM-RUNOFF hydrographs superimposed on the original observed hydrographs of Johanson (1967). It can be seen that SWMM-RUNOFF calculates similar peaks, but different rising and recession limbs from those observed. Thus, validation of the program is not accurately attained. Recall that the program does not account for (i) induced upper surface shear stresses due to rain, (ii) rain induced turbulence, (iii) transition to laminar flow, (iv) induced lower surface shear stresses due to the transverse momentum of infiltration, or (v) transition between super- and subcritical flow. These processes can be expected to produce less stable flow. James and Wylie (1999) discuss these effects, and James and Johanson (1999) develop an Initial Storage Theory that accounts for them. Real instabilities can be seen in Figure 25.15.

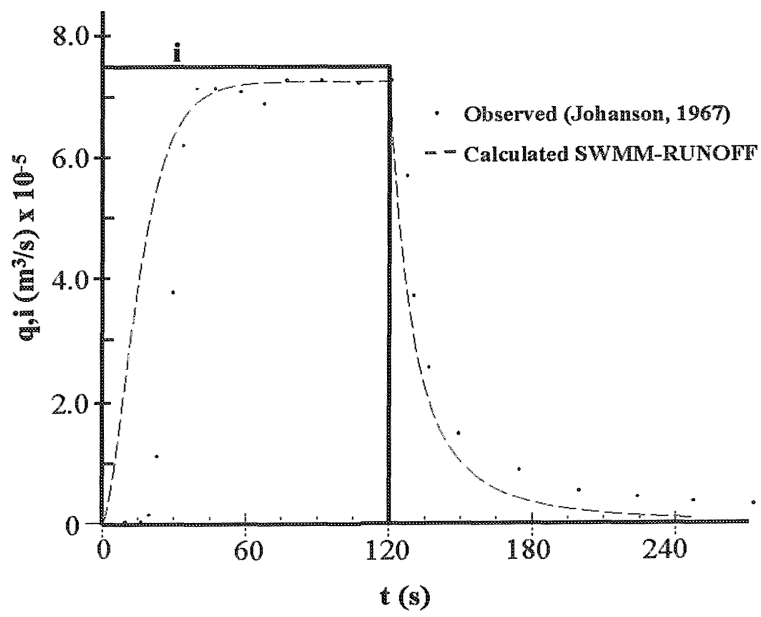

Figure 25.3 Long-duration comparison. 


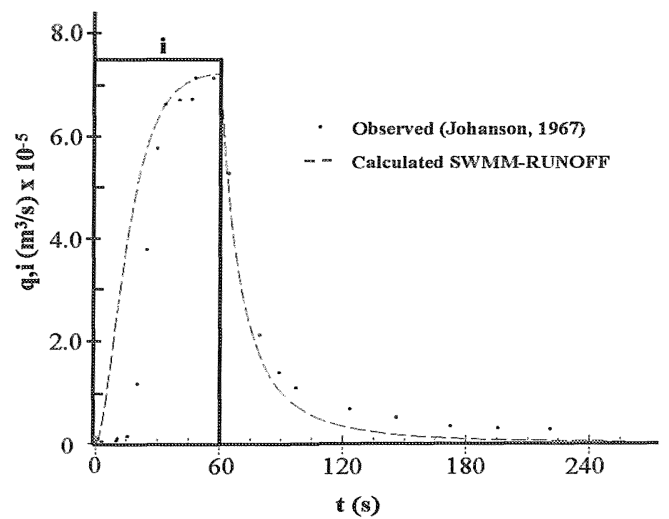

Figure 25.4 Short-duration comparison.

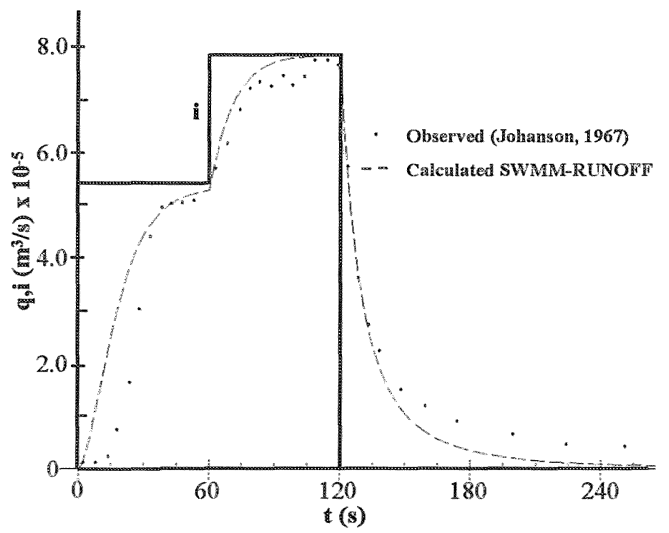

Figure 25.5 Variable increasing rainfall comparison.

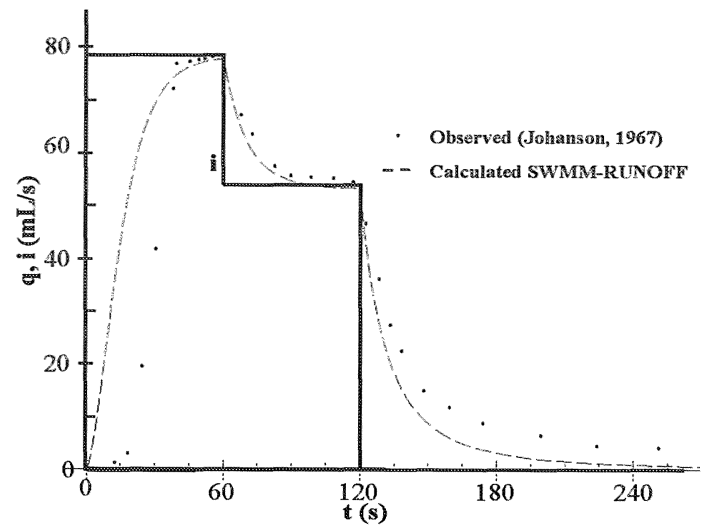

Figure 25.6 Variable decreasing rainfall comparison. 


\subsection{Storage Routing with Time Lag}

A storage-routing model was developed by Falk and Niemczynowicz (1979) and then fitted to their observations of rain on and runoff from thirteen small paved catchments in the city of Lund in Sweden. They introduced a time lag $\tau$ into the dynamic equation:

$$
S_{t-s z}=k Q_{t}{ }^{n}
$$

where:

$$
\begin{aligned}
S & =\text { storage volume }(\mathrm{mm}) \\
Q & =\text { outflow }\left(\mathrm{mm} \cdot \mathrm{mour}^{-1}\right) \\
k, n, \text { and } \tau & =\text { model parameters }
\end{aligned}
$$

The process uses a step by step procedure (Falk and Niemczynowicz, 1978). To determine the model parameter $\tau$ one must plot various relationships between runoff and storage for different values of $\tau$ and $n$. The best-fit values chosen are those that yield the least hysteresis effect (where values of runoff are different for the rising and falling limb of the hydrograph, for the same storage). The continuity equation is:

$$
\frac{d S}{d t}=I-Q
$$

where:

$$
I=\text { rain intensity, } m m \cdot \text { hour }^{-1}
$$

To give the catchment water budget for the time step $(t-2 \tau)$ to $(t-\tau)$, Equation 25.5 is changed to the discreet form:

$$
\frac{S_{t-\pi \tau}-S_{t-2 \pi}}{\Delta t}=\frac{I_{t-2 \pi}+I_{t-\pi}}{2}-\frac{Q_{t-2 \pi t}+Q_{t-\pi}}{2}
$$

$Q_{t}$ can be determined by substituting the value of $S_{(t-\tau)}$ (the only unknown variable in Equation 25.6) by the storage calculated in Equation 25.10. By expressing $Q$ and $I$ in $\mathrm{mm}^{-}$hour $^{-1}$ and $S$ in $\mathrm{mm}$, the equation becomes:

$$
Q_{t}=\frac{1}{k^{\frac{1}{n}}}\left(S_{t-2}+\frac{I_{t-2 \pi \pi}+I_{t-\pi \pi}}{120}-\frac{Q_{t-2 \pi \pi}+Q_{t-\pi \pi}}{120}\right)^{\frac{1}{n}}
$$

Falk and Niemczynowicz (1979) cite the following example:

Assume the following values for parameters $\mathrm{k}$ and $\mathrm{n}$ have been found for a specific catchment:

$$
\begin{aligned}
& k=0.215 \\
& n=0.667
\end{aligned}
$$


Knowing the rainfall intensities, the following steps will determine $Q_{t}$ : Choose an appropriate time step for $\tau$, say one minute.

Period 1 min:

$$
Q_{1}=\frac{1}{k^{\frac{l}{n}}}(0+0-0)^{\frac{1}{n}}=0
$$

Period 2 min:

$$
Q_{2}=\frac{1}{k^{\frac{1}{n}}}\left(0+\frac{0+60}{120}-0\right)^{\frac{1}{n}}=3.5 \mathrm{~mm} / \mathrm{hour}
$$

Period 3 min:

$$
Q_{3}=\frac{1}{k^{\frac{1}{n}}}\left(0.5+\frac{60+60}{120}-\frac{0+3.5}{120}\right)^{\frac{1}{n}}=17.9 \mathrm{~mm} / \mathrm{hour}
$$

The following equations can be used to determine $\bar{I}$ and $\bar{Q}$ :

$$
\begin{aligned}
& \dot{I}=\frac{I_{t-\pi}+I_{t}}{120} \\
& \bar{Q}=\frac{Q_{t-\pi}+Q_{t}}{120}
\end{aligned}
$$

The two storage terms, $\Delta S$ and $S_{t}$, can be determined using the equations:

$$
\begin{aligned}
\Delta S & =\bar{I}-\bar{Q} \\
S_{t} & =S_{t-1}+\Delta S
\end{aligned}
$$

Table 25.2 shows calculations for storage $S_{t}$ for the first 5 of 20 minutes.

Table 25.2 Storage and runoff calculations (first 5 minutes only).

\begin{tabular}{cccccccc}
\hline Time & Intensity & $\mathrm{I}$ bar & $\mathrm{Q}_{\mathrm{t}}$ & $\mathrm{Q}$ bar & $\Delta \mathrm{S}$ & $\mathrm{S}_{\mathrm{t}}$ \\
\hline min & $\mathrm{mm} /$ hour & $\mathrm{mm} / \mathrm{min}$ & $\mathrm{mm} / \mathrm{hour}$ & $\mathrm{mm} / \mathrm{min}$ & $\mathrm{mm}$ & $\mathrm{mm}$ \\
\hline 0 & 0 & 0 & 0.00 & 0.00 & 0.00 & 0.00 \\
1 & 60 & 0.5 & 0.00 & 0.00 & 0.50 & 0.50 \\
2 & 60 & 1 & 3.54 & 0.03 & 0.97 & 1.47 \\
3 & 120 & 1.5 & 17.86 & 0.18 & 1.32 & 2.79 \\
4 & 60 & 1.5 & 46.71 & 0.54 & 0.96 & 3.75 \\
5 & 0 & 0.5 & 72.80 & 1.00 & -0.50 & 3.26 \\
\hline
\end{tabular}


Shown in Figure 25.7 is the rating curve, the plot of storage (mm) vs. outflow $\left(\mathrm{mm} \cdot \mathrm{hour}^{-1}\right)$ for their example. The net rainfall used in this model is obtained from observed rainfall for the specified area by subtracting losses. In their catchment the water stored in depression storage is the only loss. They assume that only after the depression storage is filled can runoff occur - the model does not incorporate other losses such as evaporation or infiltration. By choosing $\Delta t=\tau=1$ minute, their method is evidently equivalent to using backward differences for storage, central differences for outflow, and $\tau=0$.

\subsubsection{Application to our Experimental Results:}

We now apply the method to the observations of Johanson (1967) that we have used above. Storage is computed in two ways: the first is the same cumulative method as in the Falk and Niemczynowicz example, the second uses Equation 25.7 directly ( $k$ is obtained from the slope of the outflow vs. storage plot, created using the storage determined by the cumulative method). For the second method, a value of $n$ is chosen. The two storage values calculated are compared by determining the percent difference, given by Equation 25.12 .

$$
\% \quad \text { difference }=\frac{\left(S_{t}-\text { Computed } S_{t}\right)}{S_{t}} \times 100 \%
$$

The value of $n$ is changed in the second method, and the new computed storage is again compared with the cumulative storage.

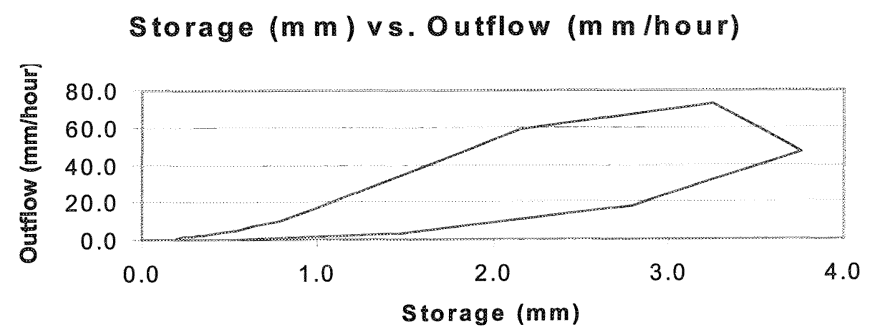

Figure 25.7 Rating curve for the Falk and Niemczynowicz example.

Figure 25.8 depicts the rating curve for the cumulative storage vs. outflow for Johanson's experimental data shown in Figure 25.9. Table 25.3 compares the two storage methods for the first 100 of 200 seconds. Results indicate that $n=1$ is better than $n=0.667$. The table also facilitates depiction of the flow transitions during shallow overland flow on pavements. 


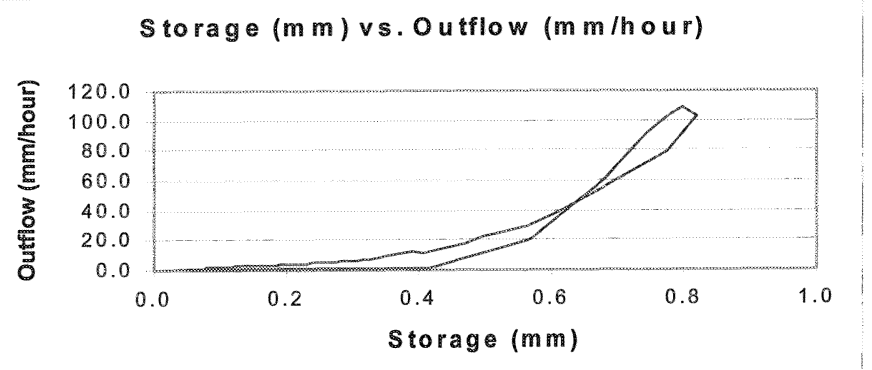

Figure 25.8 Rating curve for Johanson's data.

\subsection{Reynolds and Froude Numbers}

The tables of computations above readily allow further investigation of the concepts and effects of flow transitions discussed in the previous sections. Both the Reynolds number and the Froude number averaged over the small pavement were calculated:

$$
\text { Reynolds No. }=\frac{V d}{v}
$$

$$
\text { Froude No. }=\frac{V}{\sqrt{g d}}
$$

where:

$$
\begin{aligned}
& V=\text { runoff velocity (runoff flow/runoff area) } \mathrm{m} / \mathrm{s} \\
& d=\text { storage depth }(\mathrm{m}) \\
& v=\text { kinematic viscosity }\left(\mathrm{m}^{2} / \mathrm{s}\right) \\
& g=\text { gravitational acceleration }\left(\mathrm{m} / \mathrm{s}^{2}\right)
\end{aligned}
$$

Figures 25.9 and 25.10 show plots of the Reynolds number and the Froude number for the rainfall input used in Johanson's data. In Figure 25.9, the Reynolds number indicates laminar flow, while the Froude number indicates sub-critical flow. This is expected due to both the low volume and the low velocity of the runoff.

Further work done by Johanson included varying the rainfall intensities during the same rainfall duration as shown in Figures 25.5 and 25.6. Figures 25.11 and 25.12 show plots of the Reynolds and Froude numbers for the same increasing and decreasing rainfall intensities. Table 25.1 provides the intensities and the durations for tests 3 and 4 . 
Table 25.3 Calculations of storage for Johanson's data (first 100 secs).

\begin{tabular}{|c|c|c|c|c|c|c|c|c|}
\hline \multicolumn{3}{|c|}{ Input } & \multicolumn{3}{|c|}{ Parameter $\mathrm{n}=1$} & \multicolumn{3}{|c|}{ Parameter $\mathrm{n}=0.667$} \\
\hline 1 & 2 & 3 & 4 & 5 & 6 & 7 & 8 & 9 \\
\hline 0 & 0 & 0.00 & 0.00 & 0.00 & 0.00 & 0.00 & 0.00 & 0.00 \\
\hline 5 & 120.78 & 0.69 & 0.08 & 0.01 & 7.64 & 0.08 & 0.01 & 7.56 \\
\hline 10 & 120.78 & 0.69 & 0.25 & 0.01 & 24.32 & 0.25 & 0.01 & 24.23 \\
\hline 15 & 120.78 & 0.69 & 0.42 & 0.01 & 41.00 & 0.42 & 0.01 & 40.91 \\
\hline 20 & 120.78 & 20.44 & 0.57 & 0.20 & 36.56 & 0.57 & 0.07 & 49.52 \\
\hline 25 & 120.78 & 61.33 & 0.68 & 0.61 & 6.77 & 0.68 & 0.16 & 52.53 \\
\hline 30 & 120.78 & 91.63 & 0.74 & 0.92 & 17.38 & 0.74 & 0.20 & 53.90 \\
\hline 35 & 120.78 & 102.92 & 0.78 & 1.03 & 25.40 & 0.78 & 0.22 & 55.52 \\
\hline 40 & 120.78 & 108.55 & 0.80 & 1.09 & 28.95 & 0.80 & 0.23 & 56.81 \\
\hline 45 & 120.78 & 102.21 & 0.82 & 1.02 & 20.47 & 0.82 & 0.22 & 59.85 \\
\hline 50 & 0.00 & 79.65 & 0.78 & 0.80 & 2.15 & 0.78 & 0.19 & 58.96 \\
\hline 55 & 0.00 & 55.67 & 0.68 & 0.56 & 12.43 & 0.68 & 0.15 & 53.50 \\
\hline 60 & 0.00 & 39.46 & 0.61 & 0.39 & 22.03 & 0.61 & 0.12 & 49.89 \\
\hline 65 & 0.00 & 29.60 & 0.57 & 0.30 & 27.10 & 0.57 & 0.10 & 47.12 \\
\hline 70 & 0.00 & 25.37 & 0.53 & 0.25 & 27.52 & 0.53 & 0.09 & 44.24 \\
\hline 75 & 0.00 & 22.56 & 0.50 & 0.23 & 27.00 & 0.50 & 0.08 & 41.56 \\
\hline 80 & 0.00 & 17.62 & 0.47 & 0.18 & 29.15 & 0.47 & 0.07 & 39.99 \\
\hline 85 & 0.00 & 15.50 & 0.44 & 0.16 & 28.97 & 0.44 & 0.06 & 38.24 \\
\hline 90 & 0.00 & 13.39 & 0.42 & 0.13 & 29.07 & 0.42 & 0.06 & 36.82 \\
\hline 95 & 0.00 & 11.27 & 0.41 & 0.11 & 29.48 & 0.41 & 0.05 & 35.72 \\
\hline 100 & 0.00 & 11.98 & 0.39 & 0.12 & 27.15 & 0.39 & 0.05 & 33.89 \\
\hline
\end{tabular}

1: Time (s) 2: Rainfall intensity ( $\mathrm{mm} /$ hour)

3: Observed runoff $(\mathrm{mm} / \mathrm{hr}) \quad 4,7:$ Accumulated storage (Falk and Niemczynowicz method) 5, 8: Computed storage $\quad 6,9: \%$ Difference between storage

Time (s) vs. Rairfall (mm/hour), Runoff (mm/hour), and Reyndds No.

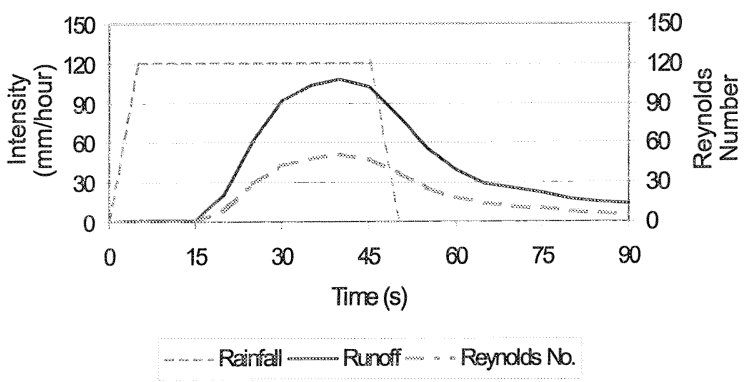

Figure 25.9 Reynolds Number for Johanson's data.

In Figures 25.11 and 25.12, the Reynolds Number indicates laminar flow, whereas the Froude Number indicates super-critical flow. Laminar supercritical flow evidently is not commonly reported in the literature. It's appearance 
Time (s) vs. Storage (mm) and Froude No.

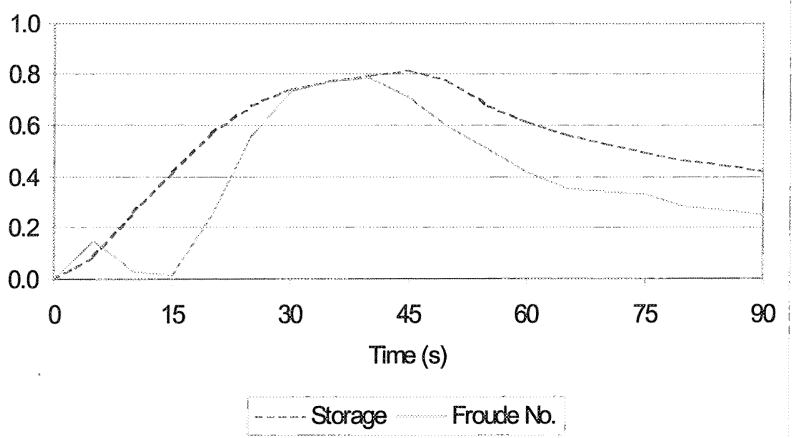

Figure 25.10 Plot Froude number for Johanson's data.

\section{Time (s) vs. Reynolds No. and Froude No.}

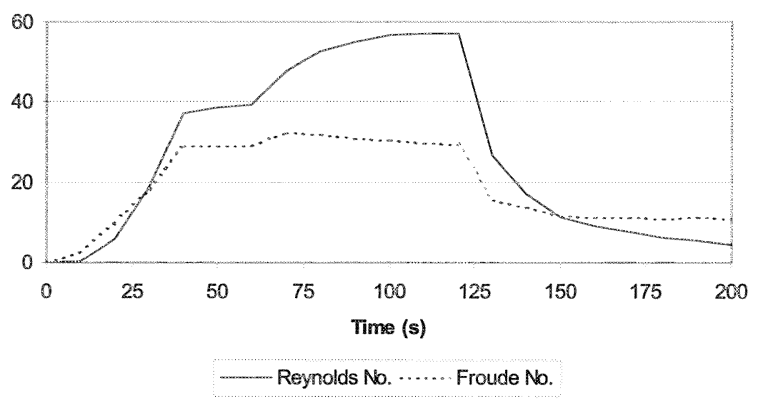

Figure 25.11 Re and Fr for Johanson's increasing rain intensity data (test 3).

Time (s) vs. Reynolds No. and Froude No.

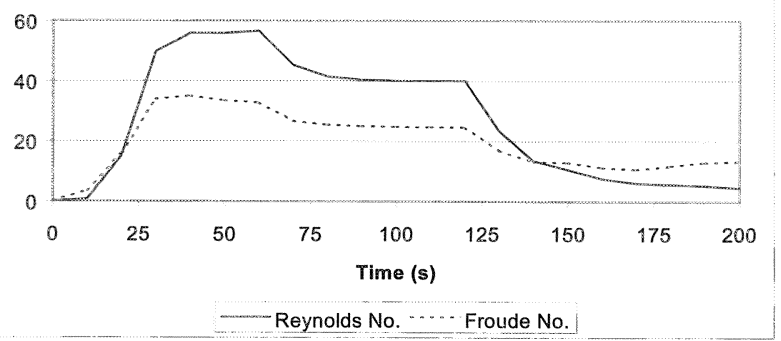

Figure 25.12 Re and Fr using Johanson's decreasing rain intensity data (test 4). 
here helps explain conditions giving rise to the anomalous hump (James and Wylie, 1999). Recall that, for a given flow condition, laminar flow is more efficient than turbulent flow. Thus the flow will appear to accelerate at the cessation of rain, when the rain-induced turbulence disappears. Calculated Froude numbers are high, but even higher Froude numbers are obtained at the tail of the runoff recession (not shown).

The rating curves for the varying rainfall intensity data are plotted in Figures 25.13 and 25.14.

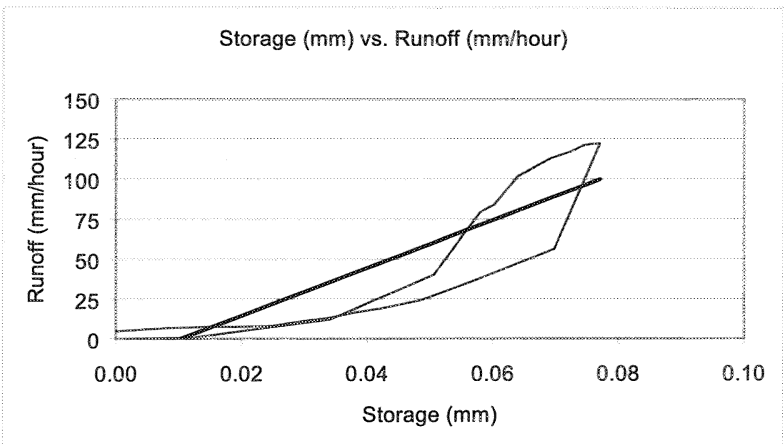

Figure 25.13 Rating curve for Johanson's increasing rain intensity data (test 3).

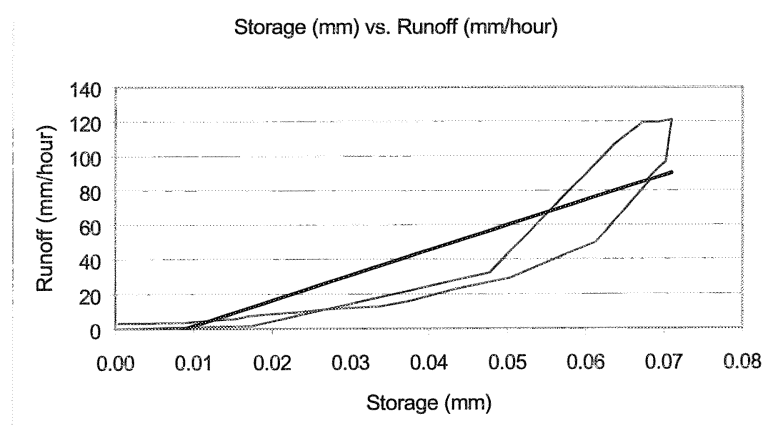

Figure 25.14 Rating curve for Johanson's decreasing rain intensity data (test 4).

How are these results to be interpreted? Thin sheet flow under light rain on a steep impervious asphalt road is shown in Figure 15. Instabilities manifest themselves in the form of a train of regular waves, moving slower at smaller depths. The RUNOFF kernel function does not explicitly include mathematics for most of the processes evident in Figure 25.15, such as (i) induced shear 
stresses at the upper surface due to the vertical transfer of rain momentum, (ii) turbulence induced by raindrop impacts, (iii) flow transition to relatively efficient laminar flow, (iv) induced shear stresses at the lower surface due to the transverse momentum of infiltration, (v) flow transition between super-and sub-critical flow. Flow transitions are usually accompanied by unstable depths, such as those seen in Figure 25.15.

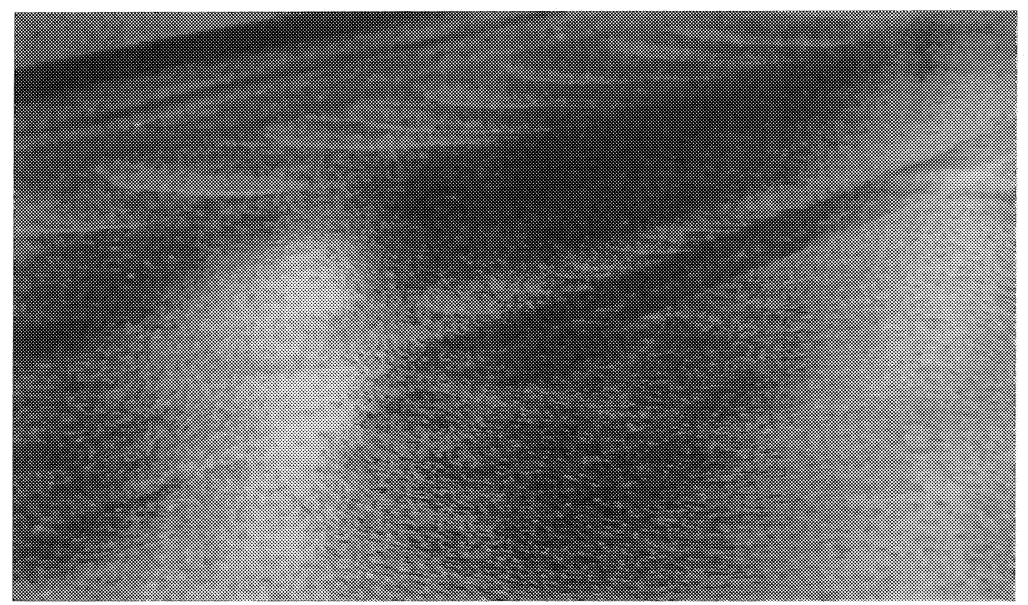

Figure 25.15 Photograph of thin overland flow on a moderately steep asphalt road under moderate rain (Source: W James, Guelph, July 2000).

Derived Reynolds Numbers were rather low, indicating laminar flow, whereas the simultaneous Froude Numbers were rather high, indicating supercritical flow. A literature search was unsuccessful in finding other examples of laminar super-critical flow, which evidently is not commonly reported.

In terms of the SWMM-RUNOFF rain-runoff kernel algorithm, however, no particular significance is imputed to these revelations, other than that the performance of the Runoff kernel nevertheless remains reasonable.

\subsection{Conclusions}

This chapter has described an investigation into the performance of the rainrunoff kernel algorithm in SWMM-RUNOFF. A SWMM Runoff input datafile was run to replicate earlier findings on a laboratory-scale pavement. PCSWMM is used to calibrate the Runoff kernel and generate plots that are compared to the experimental results obtained from a laboratory rig described earlier. The impervious pavement had a slope of $0.025 \mathrm{~m} / \mathrm{m}$, an area of $2.11 \mathrm{~m}^{2}$ and a width of $1.171 \mathrm{~m}$. A small computational time step of $1 \mathrm{~s}$ was used. 
Results demonstrated that SWMM-RUNOFF calculates similar peak flows, but different overall hydrograph shapes than those observed on the laboratory rig. Validation of the program is not proven for the rising and falling limbs of the hydrographs. However readers should recall that the program does not account for (i) induced upper surface shear stresses due to the vertical transfer of rain momentum, (ii) rain induced turbulence, (iii) flow transition to relatively efficient laminar flow, (iv) induced lower surface shear stresses due to the transverse momentum of infiltration, or (v) transition between super- and sub-critical flow, usually accompanied by unstable depths.

Further calculations were carried out to elucidate these flow transitions. A storage-lag method of routing was used to derive information for calculating transient Reynold's and Froude numbers for the overland flow process. Derived Reynolds Numbers were rather low, indicating laminar flow, whereas the simultaneous Froude Numbers were rather high, indicating super-critical flow. A literature search was unsuccessful in finding other examples of laminar super-critical flow, which evidently is not commonly reported. In terms of the SWMM-RUNOFF rain-runoff kernel algorithm, however, no particular significance is imputed to these revelations, other than that the performance of the Runoff kernel nevertheless remains reasonable.

\section{References}

Falk, J. and Niemczynowicz, J. 1979. Modelling of RunoffFrom Impermeable Surfaces. Report No. 3024 for Dept. of Water Resources Engn'rg, Lund Inst. of Tech., U. of Lund.

Huber, W.C., Dickinson, R.E, Roesner, L.A. and Aldrich, J.A. 1988. Stormwater management model user's manual, Version 4. EPA/600/3-88-001, US Environmental Protection Agency, Athens, GA.

Izzard, C.F. 1944. The surface profile of overland flow. Trans. Am. Geophys. Union, 25:959-968.

Izzard, C.F. 1946. Hydraulics of runoff from developed surfaces. Proc. Highway Research Board. 26:129-150.

Izzard, C.F. and Augustine, M.T. 1943. Prelim. report on analysis of runoff from simulated rainfall on a paved plot. Trans. AGU. 2:500-509.

James, W. and R.C. Johanson. 1999. "A Note on an Inherent Difficulty with the Unit Hydrograph Method." Journal of Water Management Modeling R204-01. doi: 10.14796/JWMM.R204-01.

James, W. and S.C. Wylie. 1999. "Numerical Techniques for Overland Flow from Pavement." Journal of Water Management Modeling R206-05. doi:

10.14796/JWMM.R206-05. 
James, W., S.C. Wylie and R.C. Johanson. 1999. "A Laboratory Rig for Testing Runoff from Paved Surfaces." Journal of Water Management Modeling R206-06. doi: 10.14796/JWMM.R206-06.

Johanson, R.C. 1967. System analysis of the rainfall-runoff process. M.Sc.Eng. thesis, University of Natal, Durban, South Africa. 